\title{
Manufacture of Acid Gels from Skim Milk Using High-Pressure Homogenization
}

\author{
A. Hernández and F. M. Harte ${ }^{1}$ \\ Department of Food Science and Technology, University of Tennessee, Knoxville 37996-4539
}

\section{ABSTRACT}

The effect of high-pressure homogenization (HPH) alone or in combination with a thermal treatment (TT) was investigated for the manufacture of acid gels from skim milk. Raw skim milk was subjected to HPH (0 to $350 \mathrm{MPa})$ or a TT $\left(90^{\circ} \mathrm{C}, 5 \mathrm{~min}\right)$, or both, in the following processing combinations: 1) HPH, 2) HPH followed by TT, 3) TT followed by HPH, 4) TT, and 5) raw milk (control). After treatments, $\mathrm{L}^{*}$ (lightness) values were measured, and then skim milk was acidified with $3 \%$ glucono- $\delta$-lactone and rheological properties $\left(\mathrm{G}^{\prime}\right.$ and gelation time), and whey holding capacity was evaluated. Treatments in which HPH and TT were combined showed greater $\mathrm{L}^{*}$ values than those in which just HPH was applied. In all treatments, the $L^{*}$ values decreased as the pressure was increased up to $300 \mathrm{MPa}$ with little change afterward. Gelation times were lower when HPH was combined with TT compared with the acid skim milk gels that were just pressure treated. The final $G^{\prime}$ in gels obtained from skim milk subjected to the combined process (HPH and TT) was greater and pressure-dependent compared with all other gels. A maximum $\mathrm{G}^{\prime}(\sim 320 \mathrm{~Pa})$ was observed with skim milk subjected to a combination of thermal processing before or after $\mathrm{HPH}$ at $350 \mathrm{MPa}$. Acid gels obtained from $\mathrm{HPH}$ milk at $350 \mathrm{MPa}$ showed a linear decrease in whey holding capacity over time, retaining $20 \%$ more whey after centrifugation for 25 min compared with samples treated at lower pressures and all other treatments. Our results suggest that HPH in combination with TT can be used to improve the rheological properties and stability of yogurt, thus decreasing the need for additives.

Key words: high-pressure homogenization, thermal treatment, yogurt rheology, whey holding capacity

Received May 1, 2008.

Accepted June 24, 2008.

${ }^{1}$ Corresponding author: fede@utk.edu

\section{INTRODUCTION}

Dairy products are part of the regular diet of many people, and yogurt has gained important recognition throughout the world because of its nutritional benefits (Lucey et al., 1998a). Yogurt is the result of milk fermentation by lactic acid bacteria through the conversion of lactose in lactic acid. There are 3 main types of yogurt: plain-set style, fruit-on-the-bottom, and blended, which is also known as Swiss or stirred style (Lucey, 2004). The main steps in industrial yogurt manufacture include the standardization of milk (increase of total solids, adjustment of casein, whey proteins, and fat), thermal treatment (e.g., $85^{\circ} \mathrm{C}$ for $30 \mathrm{~min}$ ), homogenization (15 to $20 \mathrm{MPa}$ ), addition of bacterial culture (Lactobacillus delbrueckii ssp. bulgaricus and Streptococcus salivarius ssp. thermophilus), fermentation, cooling, and storage. Depending on the type of yogurt, sweeteners, stabilizers, and fruit pieces may be also added (Needs et al., 2000; Lucey, 2004).

In the manufacture of yogurt, pretreatment of milk (standardization, thermal treatment, and homogenization) is a crucial factor that determines the quality of the final product (Needs et al., 2000; Lucey, 2004; Sandra and Dalgleish, 2005; Serra et al., 2007). The thermal processing of milk promotes the denaturation of B-lactoglobulin and a-lactalbumin, exposure of their thiol (-SH) groups, and the subsequent disulfide interaction with $\mathrm{k}$-casein from the casein micelle surface. The coating of the casein micelles by denatured whey proteins prevents the coalescence of micelles from fermentation-induced reduction of $\mathrm{pH}$ to the isoelectric point ( 4.6) of the casein proteins. Thus, yogurts made from thermally treated milk exhibit a thin casein micelle matrix that imparts firmness and increases whey retention (Walsh-O'Grady et al., 2001).

Low-fat yogurts require the addition of stabilizers (usually polysaccharides or gelatin) to provide firmness and avoid syneresis (Lucey, 2004). Controlling the texture and the use of fewer stabilizers and additives is one of the biggest challenges in yogurt manufacture (Lucey, 2004). Acid milk gels can be obtained by addition of glucono- $\delta$-lactone, which is converted to gluconic acid, simulating the acidification of milk during 
the fermentation process in yogurt manufacture. Acid gels have been used as models in the study of yogurt manufacture and its rheological properties (Lucey et al., 1998a; Walsh-O'Grady et al., 2001; Lee and Lucey, 2004). Emerging technologies (e.g., high hydrostatic pressure) have been recently studied to improve the rheological properties and decrease whey separation in yogurt (Harte et al., 2003; Lanciotti et al., 2004; Sandra and Dalgleish, 2005; Serra et al., 2007).

Walsh-O'Grady et al. (2001) compared the use of high hydrostatic pressure (700 $\mathrm{MPa}, 20 \mathrm{~min})$ and thermal treatment $\left(90^{\circ} \mathrm{C}, 10 \mathrm{~min}\right)$ in the rheology of acid-set gels, suggesting that the mechanism used to denature whey proteins (pressure or heat) caused a different degree of interactions between caseins and whey proteins and the dissociation of the casein micelle at pressures $>250 \mathrm{MPa}$ (Needs et al., 2000; Huppertz et al., 2004; Harte et al., 2007). Similar observations were found by Needs et al. (2000), and modifications in the physical properties of yogurts or acid gels have been reported using high hydrostatic pressure (Harte et al., 2003; Sandra and Dalgleish, 2005). The main disadvantage of high hydrostatic pressure is that it remains a relatively expensive batch-processing operation (Lanciotti et al., 2004).

The dissociation of the casein micelle using highpressure homogenization (HPH) was reported by Roach and Harte (2008), leading to modifications in the properties of products subjected to this process (Serra et al., 2007). Current HPH can achieve up to $400 \mathrm{MPa}$ with the advantage of being a continuous process in which physical forces such as cavitation, turbulence, impact, and shearing contribute to the treatment (Middelberg, 1995; Pandolfe, 1999). The objective of this work was to investigate the effect of HPH alone or in combination thermal processing to improve the rheology and whey holding capacity (WHC) of a low-fat yogurt model.

\section{MATERIALS AND METHODS}

\section{Milk Treatment}

Raw milk was obtained from the dairy farm of the University of Tennessee and centrifuged $(1,500 \times g, 15$ min) using a Sorvall RC 5B Plus centrifuge equipped with a SLA-1500 rotor (Kendro, Newtown, CT) to remove fat. Sodium azide $0.02 \%$ (Fisher Scientific, Fair Lawn, NJ) was added to the skim milk to prevent bacterial growth and was kept at $4^{\circ} \mathrm{C}$ until it was required for the treatments the same or the next day. Skim milk was subjected to $\mathrm{HPH}$ in the range of 0 to $350 \mathrm{MPa}$, using a high-pressure homogenizer (model nG12500, Stansted Fluid Power Ltd., Essex, UK), alone or in combination with a thermal process (TT;

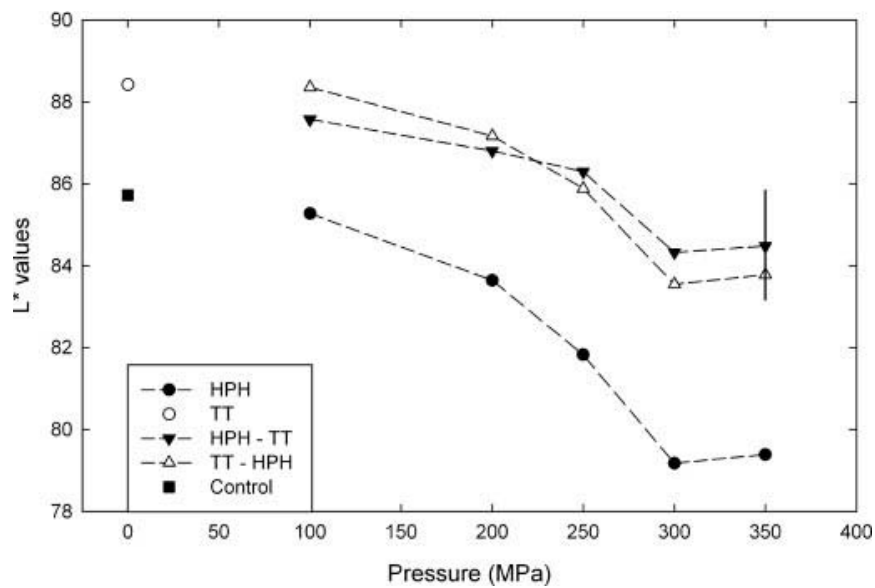

Figure 1. Effect of high-pressure homogenization (HPH; 0 to 350 $\mathrm{MPa}$ ) or thermal treatment $\left(\mathrm{TT} ; 90^{\circ} \mathrm{C}, 5 \mathrm{~min}\right)$, or both, on the $\mathrm{L}^{*}$ (lightness) values of skim milk. Bar is a $95 \%$ confidence interval for any mean, standard deviation $=1.18$.

$90^{\circ} \mathrm{C}$ for $5 \mathrm{~min}$ ) using a water bath (Isotemp 3016D, Fisher Scientific). The temperature of the skim milk before homogenization was $\sim 20^{\circ} \mathrm{C}$. Immediately after homogenization, the temperature changed linearly from 20 to $78^{\circ} \mathrm{C}$ for 0 to $350 \mathrm{MPa}$ of homogenization pressure, respectively. A tubular heat exchanger was connected after the homogenization valve to cool down the samples to room temperature, and then the samples were kept at $4^{\circ} \mathrm{C}$ for later experiments. For TT, milk samples in flasks were allowed to reach room temperature and then put inside a controlled temperature water bath. Temperature was monitored in the milk samples, and an average of 5 min was required to reach the target temperature $\left(90^{\circ} \mathrm{C}\right)$. At the end of the TT treatment, the samples were immediately cooled using a water bath set at $20^{\circ} \mathrm{C}$. The time between $\mathrm{HPH}$ and TT treatments was less than $30 \mathrm{~min}$. The following processing combinations were tested: 1) high-pressure homogenization (HPH), 2) HPH followed by thermal processing (HPH-TT), 3) thermal processing followed by HPH (TT-HPH), 4) thermal processing (TT), and 5) raw milk (control).

\section{Color and Rheological Properties}

Immediately after processing, $L^{*}$ values (lightness from 0 to 100) of treated milks and controls were recorded as the average of 3 replications using a Hunter colorimeter (Hunter Associates Laboratory, Reston, VA) calibrated with black-and-white standard tiles (standard light source D65 and $10^{\circ}$ observer) and placing the samples in a glass cup protected from the external light. Samples were transferred to a refrigerator set at $4^{\circ} \mathrm{C}$ after color determinations. At regular intervals, 
samples were removed from the refrigerator and 3\% (wt/vol) glucono- $\delta$-lactone (Sigma-Aldrich, St. Louis, MO) was added. The samples were stirred for $5 \mathrm{~min}$ and then transferred to a rheometer (model AR-2000, TA Instruments, New Castle, DE) equipped with cupand-bob geometry (stator inner radius: $15 \mathrm{~mm}$; rotor outer radius: $14 \mathrm{~mm}$; height: $42 \mathrm{~mm}$; sample volume: $14 \mathrm{~mL}$ ). A thin layer of mineral oil was added to the top surface of the sample to prevent evaporation during rheological measurements. Viscoelastic properties (storage modulus, $\mathbf{G}^{\prime}$ ) were monitored every $30 \mathrm{~s}$ during $110 \mathrm{~min}$ at $1.00 \mathrm{~Hz}$ oscillation frequency, $0.01 \%$ strain, and a constant temperature of $25^{\circ} \mathrm{C}$. The gelation time was defined as the time where the samples had a $\mathrm{G}^{\prime}$ $\geq 1 \mathrm{~Pa}$ (van Marle and Zoon, 1995) and firmness as the value of $\mathrm{G}^{\prime}$ at the end of the test (110 min).

\section{WHC}

Glucono- $\delta$-lactone was added (3\%; wt/vol) to $40 \mathrm{~mL}$ of processed milk samples in plastic centrifuge tubes and left for $3 \mathrm{~h}$ at room temperature to evaluate their WHC. The samples were then centrifuged (Sorvall RC 5B Plus, Kendro) at 5-min intervals for a total of 30 min at $2,400 \times g$, using a SS-34 rotor. At each interval time, expelled whey was carefully removed using a small pipette, the sample was weighed, and was then returned to the centrifuge. The WHC was calculated using the following formula and expressed as WHC (\%) $=[1-($ weight of total whey expelled after centrifugation at each time interval/initial weight of sample)] $\times$ 100.

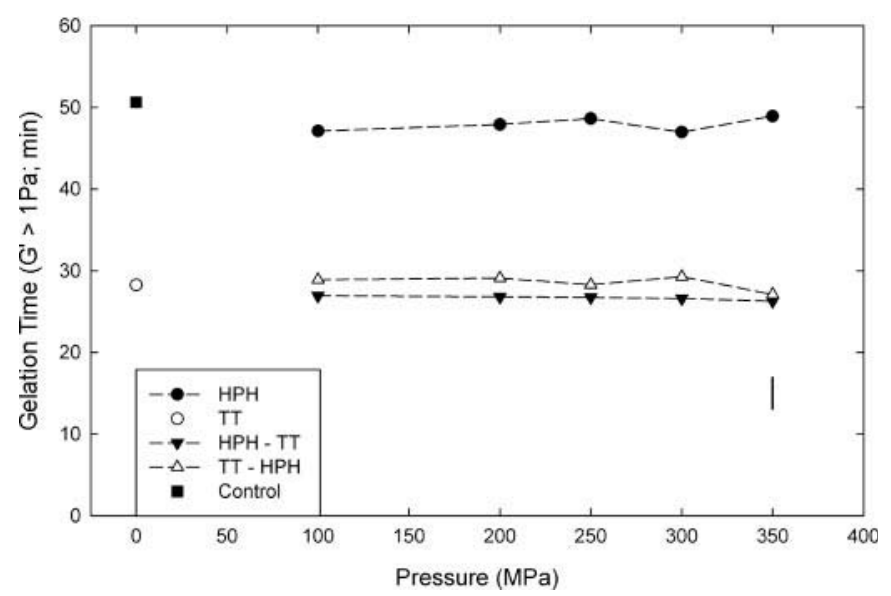

Figure 2. Effect of high-pressure homogenization (HPH; 0 to 350 $\mathrm{MPa}$ ) or thermal treatment $\left(\mathrm{TT} ; 90^{\circ} \mathrm{C}, 5 \mathrm{~min}\right)$, or both, on the gelation times $\left(\mathrm{G}^{\prime} \geq 1 \mathrm{~Pa}\right)$ of acid gels from skim milk acidified with $3 \%$ glucono- $\delta$-lactone. Bar is a $95 \%$ confidence interval for any mean, standard deviation $=1.69 \mathrm{~min}$.

\section{Experimental Design and Data Analysis}

Experiments (5 treatments) were performed in 3 independent replications, and results are presented as the mean of triplicates. Color determination was performed in triplicate for each replication; rheological properties and WHC were carried out once for each replication. Results were analyzed as a completely randomized block design with 3 blocks. Each batch of milk subjected to a combination of HPH or TT constituted a block. The Student's $t$-distribution was used to generate $95 \%$ confidence intervals for any mean in those cases in which ANOVA showed significant differences. Data were analyzed using SAS software, version 9.1 (SAS Institute, Cary, NC).

\section{RESULTS AND DISCUSSION}

\section{Color of Milk Samples}

In all milk samples, increasing the homogenization pressure up to $300 \mathrm{MPa}$ caused a significant decrease in the $\mathrm{L}^{*}$ values, with little changes above $300 \mathrm{MPa}$ (Figure 1). In samples in which HPH was combined with TT (after or before HPH processing), the $\mathrm{L}^{*}$ values were greater than in samples in which milk was subjected to HPH only. No significant differences on $\mathrm{L}^{*}$ values were observed for samples receiving TT before HPH vs. samples receiving TT after HPH. Samples with just TT had greater $L^{*}$ values compared with those without treatment (control) and those with just $\mathrm{HPH}$.

High-pressure homogenization is a combined process in which pressure, temperature, and shear (Middelberg, 1995; Pandolfe, 1999) promote the dissociation of casein micelles. High hydrostatic pressure itself is known to cause dissociation of the casein micelle, when milk is subjected to pressure in the 250 to $300 \mathrm{MPa}$ range (Needs et al., 2000; Harte et al., 2003, 2007; Huppertz et al., 2006), thus decreasing $L^{*}$ values. Harte et al. (2003) found that $\mathrm{L}^{*}$ values in milk would be similar to those of untreated samples when milk was subjected to high temperature $\left(85^{\circ} \mathrm{C}, 30 \mathrm{~min}\right)$ after high hydrostatic pressure treatment, indicating micelle reaggregation.

Roach and Harte (2008) reported a reduction of the casein micelle apparent diameter in skim milk subjected to $\mathrm{HPH}$ up to $\sim 200 \mathrm{MPa}$, with little additional change in the 200 to $350 \mathrm{MPa}$ pressure range. Similar observations have been found in the fat globule size of milk (Hayes et al., 2005). It is hypothesized that the increase in $\mathrm{L}^{*}$ values and apparent diameter in casein micelles when milk is subjected to homogenization above $250 \mathrm{MPa}$ is the result of a shear-induced increase in temperature, promoting strong hydrophobic interac- 
tions among dissociated casein proteins (i.e., pressuredissociated casein micelles would be reaggregated into newly formed micelles due to high temperature in the homogenization valve). Our results are in agreement with those from Serra et al. (2008), who found lower L* values in raw skim milk and skim milk $\mathrm{HPH}$ treated (100 to $300 \mathrm{MPa}$ ) compared with heat-treated milk $\left(90^{\circ} \mathrm{C}, 90 \mathrm{~s}\right)$.

\section{Gelation and Rheological Properties of Yogurt Models}

Gelation Time. Acid gels obtained from skim milk subjected to TT exhibited lower gelation times ( 28 min) than those subjected to HPH alone or where no pressure was applied ( 48 min; Figure 2$)$. No significant differences were observed in gelation time for acid gels obtained from skim milk subjected to homogenizing pressures in the 0 to $350 \mathrm{MPa}$ range.

Our results contradict those from Serra et al. (2008), who found greater aggregation rates in $\mathrm{HPH}$-treated skim milk (100 to $300 \mathrm{MPa})$ than heat-treated $\left(90^{\circ} \mathrm{C}\right.$, 90 s) skim milk, suggesting that this observation was the result of increased surface allowing greater interaction from disrupted caseins. The active participation of thermally denatured whey proteins in the gel formation and aggregation processes may be responsible for the altered microstructure of yogurt gels made from heated milks (Lucey et al., 1998b). Milk homogenized at pressure in the 300 to $350 \mathrm{MPa}$ range is subjected to shear-induced denaturing temperatures $\left(73\right.$ and $78^{\circ} \mathrm{C}$, respectively). However, the short residence time $(<2 \mathrm{~s})$ is not enough to cause extensive denaturation of whey proteins (Dannenberg and Kessler, 1988). Gracia-Julia et al. (2008) studied the effect of dynamic high pressure (100 to $300 \mathrm{MPa})$ on aggregation of whey protein isolates compared with short TT (59 to $85^{\circ} \mathrm{C}$ for $\sim 4 \mathrm{~s}$ ), suggesting than in TT, there is a formation of disulfide bonds, whereas in dynamic high pressure, there is a predominance of hydrophobic interactions.

When treatments were combined (HPH before or after TT), similar values in gelation time were found ( $28 \mathrm{~min})$, and no significant differences were observed regardless of the order of the treatments (i.e., samples receiving $\mathrm{HPH}$ before TT vs. samples receiving $\mathrm{HPH}$ after TT). Similarly, no significant differences were found in gelation time as effects of the different homogenizing pressures in the 0 to $350 \mathrm{MPa}$ range for both combined treatments (HPH before TT or HPH after TT). Gelation times of acid gels obtained by combined treatments were lower than those from skim milk without treatment (control) and those in which only HPH was applied ( 48 min). However, no significant differences

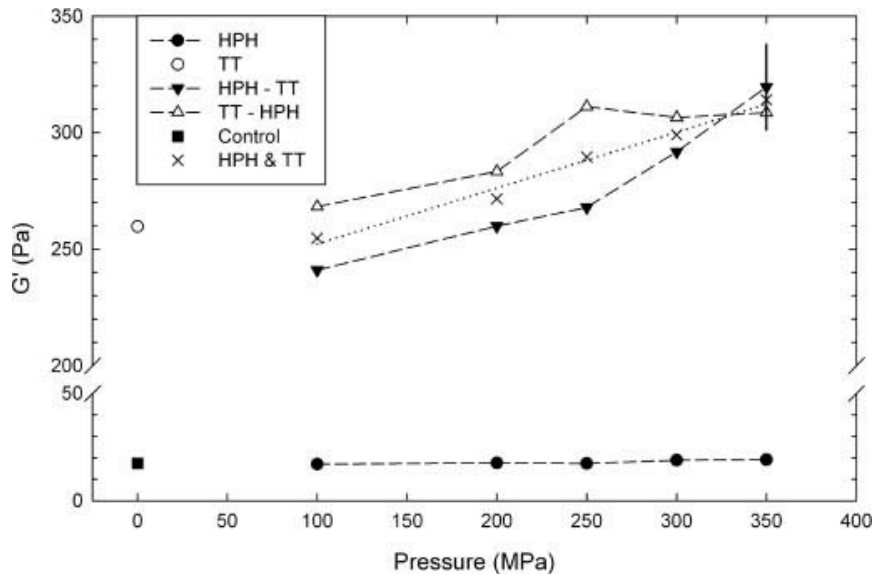

Figure 3. Maximum storage modulus ( $\mathrm{G}^{\prime}$ in $\mathrm{Pa}$; at $\left.110 \mathrm{~min}\right)$ of milk acidified with $3 \%$ glucono- $\delta$-lactone after high-pressure homogenization (HPH; 0 to $350 \mathrm{MPa}$ ) or thermal treatment $\left(\mathrm{TT} ; 90^{\circ} \mathrm{C}, 5\right.$ min), or both. Bar is a $95 \%$ confidence interval for any mean. The dotted line is the linear regression of the average of HPH-TT and TT-HPH, standard deviation $=16.24 \mathrm{~Pa}$.

were observed compared with acid gels obtained from skim milk subjected to TT only.

Our observations are in agreement with those from Walsh-O'Grady et al. (2001), who found lower gelation times in simulated yogurt milk acidified with glucono$\delta$-lactone when samples were subjected to a TT treatment $\left(90^{\circ} \mathrm{C}, 10 \mathrm{~min}\right)$ alone or in combination with high hydrostatic pressure (700 $\mathrm{MPa}, 20 \mathrm{~min})$ and greater gelation times when samples were pressure-treated. A TT treatment (e.g., $90^{\circ} \mathrm{C}, 5 \mathrm{~min}$ ) promotes the complete denaturation of whey proteins, which associate with caseins facilitating the gel formation and therefore decreasing the gelation time (Walsh-O'Grady et al., 2001).

Firmness. Acid gels obtained from skim milk subjected to TT showed greater $\mathrm{G}^{\prime}$ values $(\sim 260 \mathrm{~Pa}) \mathrm{com}$ pared with those obtained from skim milk subjected to $\mathrm{HPH}(\sim 18 \mathrm{~Pa})$ or without treatment (control; Figure 3$)$. No significant differences were observed in firmness for acid gels obtained from milk subjected to the different homogenizing pressures in the 0 to $350 \mathrm{MPa}$ range, suggesting that casein micelle dissociation alone is not enough to promote firmer yogurt gels.

Greater $\mathrm{G}^{\prime}$ values have been reported in the literature for yogurts prepared using hydrostatic pressuretreated milk compared with those from heat-treated milk (Needs et al., 2000). These authors also reported that the pressure-treated samples were less firm and less cohesive than yogurts from heat-treated milk. Our results are also in agreement with Serra et al. (2008), who reported that firmer yogurts were produced from heat-treated milk $\left(90^{\circ} \mathrm{C}, 90 \mathrm{~s}\right)$ compared with gels obtained from HPH milk in the 100 to $300 \mathrm{MPa}$ range. 

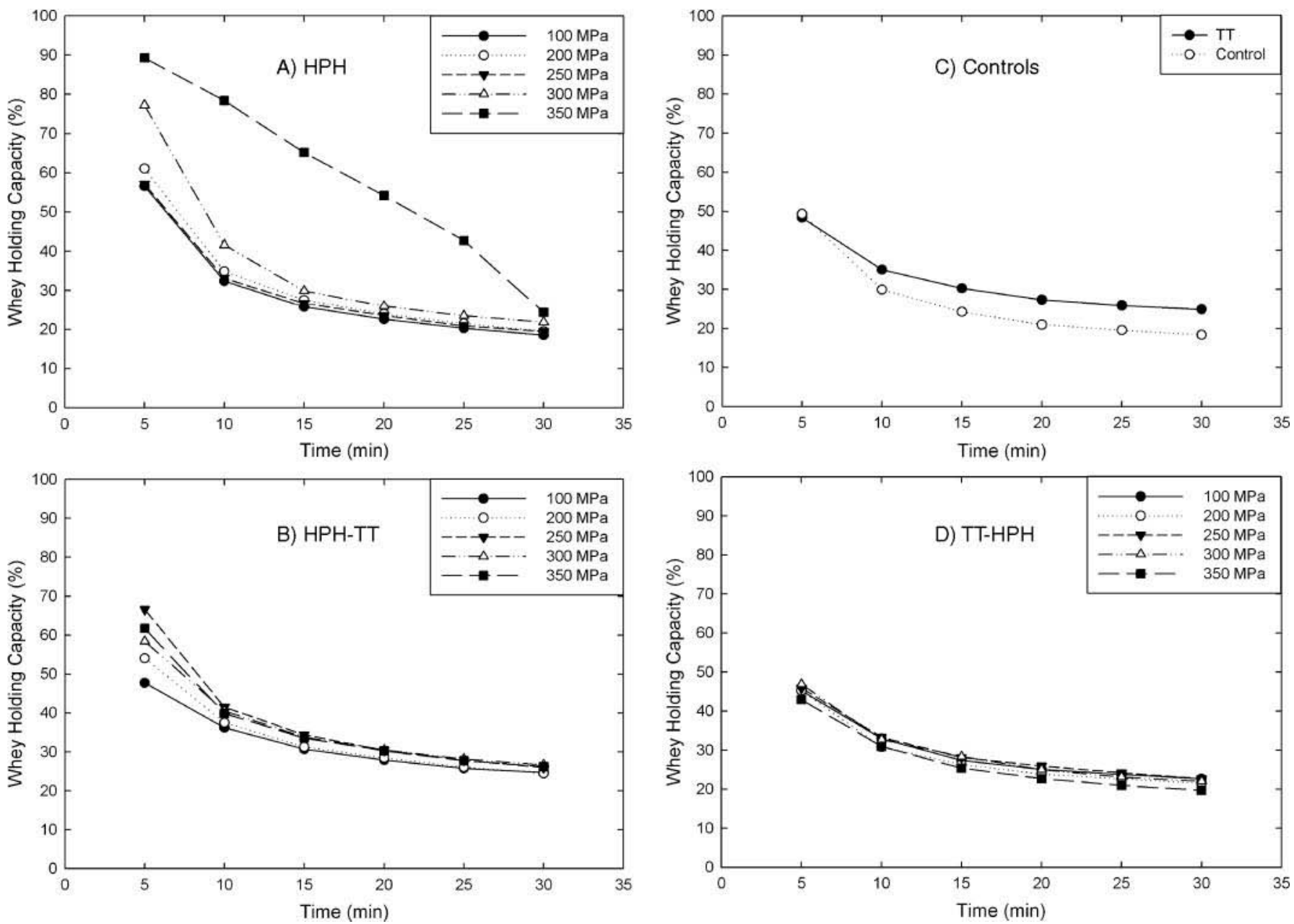

Figure 4. Whey holding capacity (WHC) in acid gels manufactured with skim milk subjected to A) high-pressure homogenization, 0 to $350 \mathrm{MPa}(\mathrm{HPH})$; B) high-pressure homogenization, 0 to $350 \mathrm{MPa}$, followed by a thermal treatment, $90^{\circ} \mathrm{C}, 5 \mathrm{~min}(\mathrm{HPH}-\mathrm{TT})$; C) control (raw milk) and thermal treatment, $90^{\circ} \mathrm{C}, 5 \mathrm{~min}(\mathrm{TT})$; and D) thermal treatment, $90^{\circ} \mathrm{C}, 5 \mathrm{~min}$, followed by high-pressure homogenization, 0 to 350 $\mathrm{MPa}(\mathrm{TT}-\mathrm{HPH})$

Our data indicated that in acid gels made with $\mathrm{HPH}$ milk, the whey proteins are not completely denatured and therefore the gel network cannot be optimally formed. Serra et al. (2007) suggested that HPH causes extensive rearrangements and aggregation of proteins causing the lower $\mathrm{G}^{\prime}$ values.

Increased solid-like behavior was observed on acid gels obtained from milk processed by both HPH and TT when compared with all other treatments, regardless of thermally processing the milk before or after homogenization. A pressure-dependent increase in the solid-like behavior of the final gels was also observed (Figure 3). The final $\mathrm{G}^{\prime}$ in gels obtained from skim milk subjected to the combined process was pressure-dependent, with a maximum $\mathrm{G}^{\prime}(\sim 320 \mathrm{~Pa})$ from acid gels made from skim milk subjected to a combination of thermal processing before or after $350 \mathrm{MPa}$ of homogenization pressure. Harte et al. (2003) reported greater $\mathrm{G}^{\prime}$ values in yogurts manufactured with milk subjected to high hydrostatic pressure in the 300 to $400 \mathrm{MPa}$ range combined with a TT $\left(85^{\circ} \mathrm{C}, 30 \mathrm{~min}\right)$, which is in agreement with our results. The similarity of our results and those obtained using high hydrostatic pressure suggests that $\mathrm{HPH}$ in the 250 to $350 \mathrm{MPa}$ range primarily affects the casein micelle and has little effect on the whey protein fraction of milk because of the short time exposure to denaturing temperatures.

\section{WHC}

Acid gels obtained from $\mathrm{HPH}$ milk at $350 \mathrm{MPa}$ showed a linear decrease in WHC over time com- 
pared with samples treated at lower pressures, in which the WHC rapidly decreased during the first 10 min of centrifugation (Figure 4A). This linear reduction in WHC was not observed in model yogurts from any other processing condition. The WHC of samples treated at $350 \mathrm{MPa}$ after centrifugation for 25 min was $43 \%$, whereas at lower pressures, the WHC was $22 \%$. Samples subjected to TT or without treatment (control) showed a fast reduction in WHC during the first 15 min of centrifugation and a slow decrease afterwards (similar to HPH samples treated at $<350 \mathrm{MPa}$ ), with the TT samples retaining $\sim 6 \%$ more whey over time in comparison to the control and HPH samples treated at $<350 \mathrm{MPa}$ (Figure 4A and 4C). Serra et al. (2007) found lower rates of whey expelled in yogurt samples made with milk treated at $\mathrm{HPH}>200 \mathrm{MPa}$ than those prepared with milk just with a TT $\left(90^{\circ} \mathrm{C}, 90 \mathrm{~s}\right)$, which is in agreement with our results.

When TT and HPH treatments were combined, similar results to other treatments (except HPH samples at $350 \mathrm{MPa}$ ) were observed in $\mathrm{WHC}$, in which a rapid reduction during the first 10 min of centrifugation followed by a slow decrease was observed (Figure 4B and $4 \mathrm{D})$. The WHC of acid gels manufactured combining HPH before TT showed greater retention of whey over time compared with those from TT and controls made from raw skim milk. When TT was applied before the $\mathrm{HPH}$, the samples showed lower WHC values $(\sim 3 \%)$ than the TT samples but greater values $(\sim 3 \%)$ than the untreated samples.

No significant effect on WHC due to greater processing pressure was observed in the combined HPH-TT and TT-HPH treatments. However, an average increase in WHC of approximately 6\% was observed in HPH-TT when compared with TT-HPH. Lucey et al. (1998a) found that acid skim milk gels with lower $\mathrm{G}^{\prime}$ values were more likely to expel more whey because of the weak structure. In our case, samples that had the greater $\mathrm{G}^{\prime}$ values (HPH and TT combined) did not show a clear increase in WHC as samples subjected to $\mathrm{HPH}$ at $350 \mathrm{MPa}$ that shower lower $\mathrm{G}^{\prime}$ values. Serra et al. (2008) reported lower percentages of whey expelled in yogurts obtained from skim milk subjected to HPH as an effect of the increase in pressure. These authors explained the increase in retention of water as resulting from denatured whey proteins and larger surface area of disrupted caseins. However, this does not explain the improvement in WHC of samples processed by $\mathrm{HPH}$ only. Our results suggest that the processing of milk with $\mathrm{HPH}(300$ to $350 \mathrm{MPa})$ followed by TT $\left(90^{\circ} \mathrm{C}\right.$, $5 \mathrm{~min}$ ) is the best processing method to obtain acid gels with high $\mathrm{G}^{\prime}$ WHC.

\section{CONCLUSIONS}

The pretreatments applied to milk in the manufacture of yogurt have a critical influence on the physical characteristics and quality of yogurts. The combined effect of HPH and TT affected the physical properties of acid gels obtained from skim milk by promoting both casein micelle dissociation and whey protein denaturation. The viscoelastic properties $\left(\mathrm{G}^{\prime}\right)$ of acid gels were enhanced by the combination of $\mathrm{HPH}$ and TT. The WHC of acid gels was improved when milk was subjected to HPH at $350 \mathrm{MPa}$ compared with all other processing conditions. Our results suggest that $\mathrm{HPH}$ has the potential to be used to improve the texture and stability of yogurts, thus decreasing the need for additives and stabilizers.

\section{REFERENCES}

Dannenberg, F., and H. G. Kessler. 1988. Reaction kinetics of the denaturation of whey proteins in milk. J. Food Sci. 53:258-263.

Gracia-Julia, A., M. Rene, M. Cortes-Munoz, L. Picart, T. LopezPedemonte, D. Chevalier, and E. Dumay. 2008. Effect of dynamic high pressure on whey protein aggregation: A comparison with the effect of continuous short-time thermal treatments. Food Hydrocoll. 22:1014-1032.

Harte, F., S. Clark, and G. V. Barbosa-Canovas. 2007. Yield stress for initial firmness determination on yogurt. J. Food Eng. 80:990-995

Harte, F., L. Luedecke, B. Swanson, and G. V. Barbosa-Canovas. 2003. Low-fat set yogurt made from milk subjected to combinations of high hydrostatic pressure and thermal processing. J. Dairy Sci. 86:1074-1082.

Hayes, M. G., P. F. Fox, and A. L. Kelly. 2005. Potential applications of high pressure homogenisation in processing of liquid milk. J. Dairy Res. 72:25-33.

Huppertz, T., P. F. Fox, and A. L. Kelly. 2004. High pressure treatment of bovine milk: Effects on casein micelles and whey proteins. J. Dairy Res. 71:97-106.

Huppertz, T., A. L. Kelly, and C. G. de Kruif. 2006. Disruption and reassociation of casein micelles under high pressure. J. Dairy Res. 73:294-298.

Lanciotti, R., L. Vannini, P. Pittia, and M. E. Guerzoni. 2004. Suitability of high-dynamic-pressure-treated milk for the production of yoghurt. Food Microbiol. 21:753-760.

Lee, W. J., and J. A. Lucey. 2004. Rheological properties, whey separation, and microstructure in set-style yogurt: Effects of heating temperature and incubation temperature. J. Texture Stud. 34:515-536.

Lucey, J. A. 2004. Cultured dairy products: An overview of their gelation and texture properties. Int. J. Dairy Technol. 57:7784.

Lucey, J. A., M. Tamehana, H. Singh, and P. A. Munro. 1998a A comparison of the formation, rheological properties and microstructure of acid skim milk gels made with a bacterial culture or glucono- $\delta$-lactone. Food Res. Int. 31:147-155.

Lucey, J. A., C. T. Teo, P. A. Munro, and H. Singh. 1998b. Microstructure, permeability and appearance of acid gels made from heated skim milk. Food Hydrocoll. 12:159-165.

Middelberg, A. P. J. 1995. Process-scale disruption of microorganisms. Biotechnol. Adv. 13:491-551.

Needs, E. C., M. Capellas, A. P. Bland, P. Manoj, D. MacDougal, and G. Paul. 2000. Comparison of heat and pressure treatments of 
skim milk, fortified with whey protein concentrate, for set yogurt preparation: Effects on milk proteins and gel structure. J. Dairy Res. 67:329-348.

Pandolfe, W. D. 1999. High pressure homogenisation: Latest technology expand performance and product posibilities. Chem. Process. 61:39-43.

Roach, A., and F. Harte. 2008. Disruption and sedimentation of casein micelles and casein micelle isolates under high-pressure homogenization. Innov. Food Sci. Emerg. Technol. 9:1-8.

Sandra, S., and D. G. Dalgleish. 2005. Effects of ultra-high-pressure homogenization and heating on structural properties of casein micelles in reconstituted skim milk powder. Int. Dairy J. 15:1095-1104.

Serra, M., A. J. Trujillo, P. D. Jaramillo, B. Guamis, and V. Ferragut. 2008. Ultra-high pressure homogenization-induced changes in skim milk: Impact on acid coagulation properties. J. Dairy Res. 75:69-75.

Serra, M., A. J. Trujillo, J. M. Quevedo, B. Guamis, and V. Ferragut. 2007. Acid coagulation properties and suitability for yogurt production of cows' milk treated by high-pressure homogenisation. Int. Dairy J. 17:782-790.

van Marle, M. E., and P. Zoon. 1995. Permeability and rheological properties of microbially and chemically acidified skim-milk gels. Neth. Milk Dairy J. 49:47-65.

Walsh-O'Grady, C. D., B. T. O'Kennedy, R. J. Fitzgerald, and C. N. Lane. 2001. A rheological study of acid-set "simulated yogurt milk" gels prepared from heat- or pressure-treated milk proteins. Lait 81:637-650. 